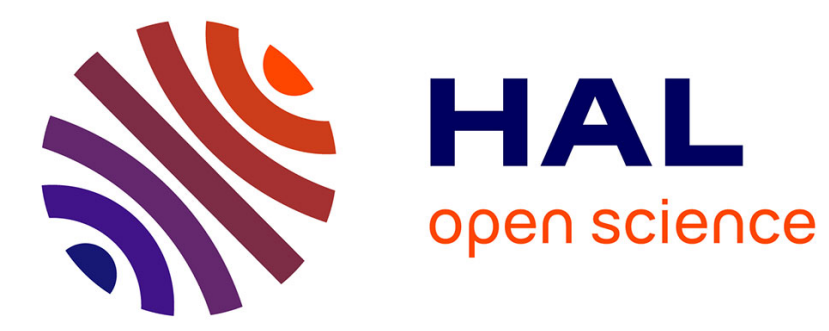

\title{
Fine-scale study of a thick stratospheric ozone lamina at the edge of the southern subtropical barrier
}

\author{
Thierry Portafaix, Béatrice Morel, Hassan Bencherif, Serge Baldy, Sophie
}

Godin-Beekmann, Alain Hauchecorne

\section{- To cite this version:}

Thierry Portafaix, Béatrice Morel, Hassan Bencherif, Serge Baldy, Sophie Godin-Beekmann, et al.. Fine-scale study of a thick stratospheric ozone lamina at the edge of the southern subtropical barrier. Journal of Geophysical Research: Atmospheres, 2003, 108 (D6), 10.1029/2002JD002741 . hal01356763

\section{HAL Id: hal-01356763 \\ https://hal.univ-reunion.fr/hal-01356763}

Submitted on 26 Aug 2016

HAL is a multi-disciplinary open access archive for the deposit and dissemination of scientific research documents, whether they are published or not. The documents may come from teaching and research institutions in France or abroad, or from public or private research centers.
L'archive ouverte pluridisciplinaire HAL, est destinée au dépôt et à la diffusion de documents scientifiques de niveau recherche, publiés ou non, émanant des établissements d'enseignement et de recherche français ou étrangers, des laboratoires publics ou privés. 


\title{
Fine-scale study of a thick stratospheric ozone lamina at the edge of the southern subtropical barrier
}

\author{
Thierry Portafaix, Béatrice Morel, Hassan Bencherif, and Serge Baldy \\ Laboratoire de Physique de l'Atmosphère, Reunion University, St. Denis, Reunion, France
}

Sophie Godin-Beekmann ${ }^{1}$ and Alain Hauchecorne

Service d'Aéronomie, CNRS, Paris, France

Received 10 July 2002; revised 29 October 2002; accepted 14 January 2003; published 29 March 2003.

[1] A large-scale transport event resulting in a thick ozone lamina originating from midlatitudes is observed in the tropical stratosphere over Reunion island $\left(55^{\circ} \mathrm{E}, 21^{\circ} \mathrm{S}\right)$. This isentropic transport was detected from stratospheric balloon-borne ozone measurements that showed the occurrence of the lamina and was investigated using different tools based on Ertel's potential vorticity (Epv) analyses. An original software (DYBAL) using surface coordinate and the equivalent length of Epv contours as diagnostic tools in conjunction with high-resolution outputs from an Epv advection model MIMOSA allows us to specify the origin of the lamina. The results indicate that a broad layer of stratospheric air was isentropically advected from midlatitudes across the southern edge of tropical reservoir and reached Reunion island on 12 July 2000. In addition, Eliassen-Palm's flux vectors, calculated from ECMWF analysis, show that planetary wave activity was quite large during that time period, with wave-breaking occurring around $30 \mathrm{~km}$, and could have driven that exchange. In contrast with analyses of filamentation events based on model and satellite data, the present study focuses on a finescale vertical survey from in situ measurements. The filament reported in this paper is characterized by a large vertical extension and is located around the maximum of ozone concentration in the tropical stratosphere $(600 \mathrm{~K})$. The analysis of such events, poorly documented in the tropics, could complement satellite studies and contribute to a better determination of the transport between the tropics and the midlatitudes. INDEX TERMS: 0341 Atmospheric Composition and Structure: Middle atmosphere-constituent transport and chemistry (3334); 3319 Meteorology and Atmospheric Dynamics: General circulation; 3334 Meteorology and Atmospheric Dynamics: Middle atmosphere dynamics (0341, 0342); 3364 Meteorology and Atmospheric Dynamics: Synoptic-scale meteorology; KEYWORDS: stratosphere, tropics, transport, ozone, laminae, barrier

Citation: Portafaix, T., B. Morel, H. Bencherif, S. Baldy, S. Godin-Beekmann, and A. Hauchecorne, Fine-scale study of a thick stratospheric ozone lamina at the edge of the southern subtropical barrier, J. Geophys. Res., 108(D6), 4196, doi:10.1029/2002JD002741, 2003.

\section{Introduction}

[2] Stratospheric meridional transport is dominated by the slow diabatic transport of air masses from the tropics to the poles, associated with the Brewer-Dobson circulation marked by large-scale air rising in the tropics and sinking in the polar regions [Holton et al., 1995]. Adiabatic exchanges along isentropic surfaces also play an important role in the stratosphere. Rossby wave breaking events at midlatitudes generate a rapid transport in which air filaments, originating from the tropics, are stretched isentropically and ultimately mixed in the surf zone [Waugh et al.,

\footnotetext{
${ }^{1}$ Now at Alfred Wegener Institut, Potsdam, Germany.
}

1994]. Furthermore, meridional gradients of Ertel's potential vorticity (Epv) and long-lived chemical species reveal the existence in the stratosphere of a dynamical barrier that controls and limits isentropic horizontal exchanges between the tropical and extratropical regions [Trepte and Hitchman, 1992; Grant et al., 1996]. Observations suggest the existence of a Tropical Stratospheric Reservoir (TSR) in which trace gas composition is distinct from that of the midlatitude stratosphere [McCormick and Veiga, 1992; Hitchman et al., 1994]. Mote et al. [1998] and Rosenlof et al. [1997] suggest a vigorous two-way transport between the TSR and the extratropics in the lowest part of the tropical stratosphere. Isentropic transport in this region is important since it can shortcut the global mean Brewer-Dobson meridional circulation. Using a middle atmosphere circulation model, Horinouchi et al. [2000] showed that the transport between the tropics and the extratropics is strongly dependent on altitude and has geographic preferences in the lower stratosphere 
with the existence of lateral privileged routes in northern hemisphere during winter. The seasonal variation of the planetary wave breaking intensity is characterized by a maximum in the winter hemisphere. Hence narrower edge gradients limiting the TSR and a more important filamentary activity are expected during this period [Waugh, 1996]. Chen et al. [1994] by modeling the transport from the TSR, have found that most of the tracer transport in the middle stratosphere takes place in the winter hemisphere. Moreover, several authors have shown that the dynamic of the TSR boundary and the intensity of the isentropic transport are dependent upon the phase of the Quasi-Biennal Oscillation (QBO) [Trepte and Hitchman, 1992; Grant et al., 1996; Choi et al., 1998]. For instance, tracers are more effectively sequestered from isentropic poleward transport processes and there is weaker mixing throughout the tropics and subtropics during the easterly phase of the QBO [Haynes and Shuckburgh, 2000; Shuckburgh et al., 2001; Baldwin et al., 2001].

[3] During isentropic transport events, air masses are carried with their dynamical and chemical characteristics. The local measurement of a constituent profile considered as a chemical tracer (e.g. ozone), when such a filament is passing through, reveals particular anomalies or laminae [Reid and Vaughan, 1991]. Several studies have shown that high resolution transport models [Orsolini et al., 1997; Hall and Waugh, 1997; Roger et al., 1999; Horinouchi et al., 2000] or contour advection with surgery [Mariotti et al.,1997; Roger et al., 1998; Heese et al., 2001] can correctly depict observed laminae. Orsolini et al. [1998] reproduced the lamination observed in midlatitude balloon profiles using reverse domain filling trajectories initialized with the Upper Atmospheric Research Satellite (UARS) data. However, most of these studies are focused on the effect of filamentation in the midlatitude stratosphere [Heese et al., 2001] and especially on the transport between pole and midlatitude surf zone [Mariotti et al., 1997; Hauchecorne et al., 2002]. In comparison with the polar vortex edge, the southern subtropical barrier has been less studied and the consequences of isentropic exchanges on tropical stratosphere are not well understood. Yet the impact of this transport with midlatitudes on tropics via laminae/ filaments could be important. This exchange is likely to contribute to the ozone budget in the tropics by bringing to this region chemically modified air masses originating from midlatitudes.

[4] Moreover, due to a lack of ground based measurements in the tropics, many of the tropical studies rely on satellites profiles [Grant et al., 1996; Roger et al., 1998, 1999] which are not able to resolve vertical fine-scale structures as well as ground based measurements. Owing to its situation near the southern edge of the TSR $\left(20^{\circ} \mathrm{S}\right)$, Reunion station presents a major interest for the observation of the exchanges between the midlatitudes and the tropical regions. The stratosphere above Reunion island is periodically influenced by air masses coming from the TSR or from the middle latitude stratosphere and the subtropical stratospheric barrier frequently passes above this geographical position. Conjointly, ongoing temperature, aerosol and ozone profiles in the stratosphere are recorded from radiosounding and lidar systems at this site. Reunion station is part of the Network for the Detection of Stratospheric
Change (NDSC). Ground-based measurements from Reunion are useful to corroborate and complement dynamical studies on the southern tropical stratosphere based on model and satellite data.

[5] This paper reports a strong isentropic exchange between the midlatitude stratosphere and the tropical stratosphere characterized by a large vertical extension (550 to $700 \mathrm{~K})$. This exchange event occurred around 12 July 2000. The study based on local ozone profiles benefits from diagnostic tools calculated with Epv. These complementary analyses give a full access to horizontal and vertical lamina development. First, the structure and the extension of the lamina are investigated from balloon-borne and DIAL system ozone measurements performed at Reunion island $\left(21^{\circ} \mathrm{S}, 55^{\circ} \mathrm{E}\right)$. Next, a dynamical barrier locating code DYBAL (Dynamical Barrier Localisation), based on an area coordinate formalism, and a high resolution Epv contour advection model MIMOSA (Modele Isentropique $\mathrm{du}$ transport Mesoechelle de l'Ozone Stratospherique par Advection) [Hauchecorne et al., 2002] are used to diagnose the origin of air masses. Both DYBAL and MIMOSA codes are working on Epv retrieved from ECMWF (European Center for Medium-Range Weather Forecast) meteorological fields. A third part is dedicated to the wave activity examination in the southern stratosphere during this period, using Eliassen Palm flux vectors. A summary of the results is given in the last section.

\section{Ozone Profile Evidence of 12 July 2000 Lamina}

[6] Since the timescale of the event we want to highlight is a few days, stratospheric ozone can be used as a chemical tracer. Ozone soundings have been launched routinely at Reunion station since 1992, every two weeks until the beginning of 1999 and each week from that date. The ozone sonde used is of ECC Z Ensci type with a $0.5 \% \mathrm{KI}$ buffered solution, and the meteorological sonde is of Vaisala RS80-18H type associated with a Tmax interface [Baldy et al., 1996; Posny et al., 2000]. The ozone measurement accuracy is around $\pm 3 \%$ in stratosphere below 10 mbar [Komhyr et al., 1995] and the precision in total ozone column measured by the ECC sonde is around 5\% [Thompson et al., 2003]. More than two hundred profiles have been recorded and a monthly climatology of ozone from this data set is available. For the present study, the statistical detection of anomalies on individual profiles is set against this climatology with a $2 \sigma$ threshold. Since temperature profile is also available from radiosoundings, ozone concentration can be plotted as a function of potential temperature.

[7] The balloon ozone profile obtained on 12 July 2000, at Reunion island, is presented in Figure 1, as a function of potential temperature. It is compared to the July climatological ozone profile. A remarkable departure from the climatological mean is observed above $500 \mathrm{~K}$. This anomaly is significant around $550 \mathrm{~K}$ and between 650 and $750 \mathrm{~K}$. It is positive below $625 \mathrm{~K}$ and negative above $625 \mathrm{~K}$. It reaches 15 to $20 \%$ around $680 \mathrm{~K}$.

[8] Moreover, a stratospheric ozone DIAL system has been recently installed at Reunion Island. This lidar was built by the University of Geneva (Switzerland) and by the Service d'Aeronomie (CNRS, France). The scientific oper- 


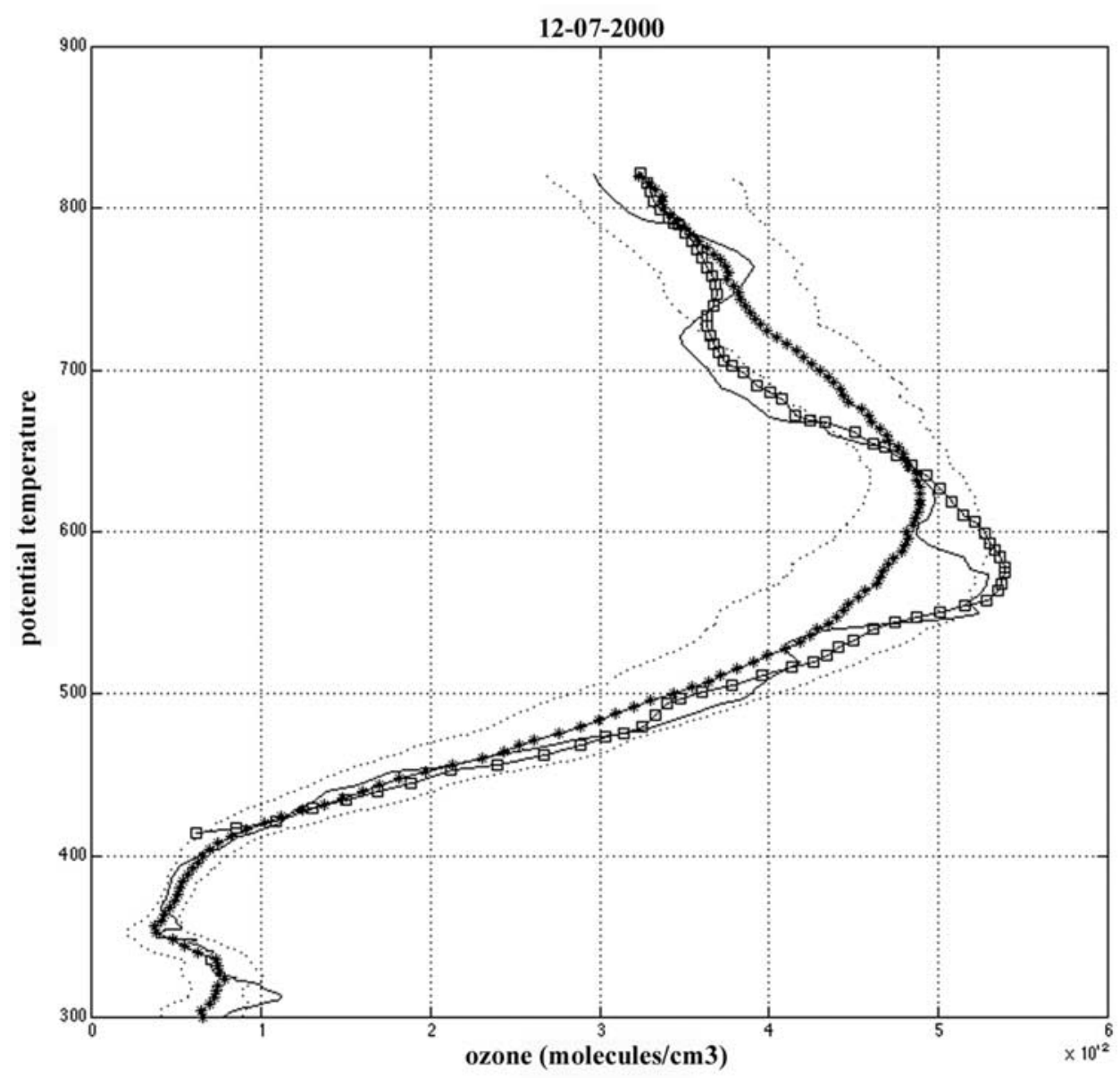

Figure 1. Comparison of 12 July 2000 ozone sounding profile (solid line) with 11 July 2000 lidar profile (squares) and with the July climatologic ozone profile (stars). Dotted lines correspond to $2 \sigma$ standard deviation shifts of the July climatology.

ation has been conducted jointly by the Service d'Aeronomie and the Laboratoire de Physique de l'Atmosphère (Réunion University, France). A DIAL ozone profile was recorded on 11 July 2000, 12 hours before the balloon sounding. This profile is superimposed on Figure 1 with squares. While the lidar profile is smoother due to the different vertical resolutions, these profiles are consistent and ozone fluctuations are coherent for both instruments between 550 and $750 \mathrm{~K}$.

[9] Orsolini and Grant [2000] used a chemical transport model to establish a global climatology of $\mathrm{N}_{2} \mathrm{O}$ lamination events for all seasons, and $20-25 \mathrm{~km}$ altitude range. They concluded that the wintertime middle stratosphere in the southern hemisphere is more zonal than its northern hemisphere counterpart. In this context, the observed lamina of 12 July 2000 should be representative of a typical exchange event through the southern edge of the southern tropical stratosphere in winter.

[10] The large vertical extension and also the high level of occurrence $(25-26 \mathrm{~km})$ of the present lamina contrast with the laminar structures previously reported in the northern hemisphere, generally in the lowest part of the stratosphere [Chen et al., 1994; Grant et al., 1998; Roger et al., 1999; Heese et al., 2001]. Particularly, Grant et al. [1998], from statistics on tropical ozone soundings, found that laminae are restrained to altitudes below $21 \mathrm{~km}$ and are not related to a significant Rossby wave activity.

[11] However, Jost et al. [1998] have also detected several $\mathrm{N}_{2} \mathrm{O}$ laminae instances inside the TSR at high altitude $(700,775,850 \mathrm{~K})$ by in situ measurements aboard the Observations from Middle Stratosphere (OMS) balloon. They concluded that these laminae resulted from Rossby wave-breaking events that led the transport of midlatitude air into the deep tropics.

[12] In order to further investigate the vertical extent of the anomaly observed on the ozone profiles, we use for comparison annual ozone profiles obtained from the Halogen Occultation Experiment (HALOE) on board of the Upper Atmosphere Research Satellite (UARS) [Russell et al., 1993]. Figure 2 presents three climatological profiles calculated from 1991-2000 HALOE data. The first one corresponds to Reunion island latitude $\left(21^{\circ} \mathrm{S}\right)$, the second to latitudes close to $10^{\circ} \mathrm{S}$ and the third to midlatitudes around $40^{\circ} \mathrm{S}$. Provided that ozone is conservative during a short timescale transport, Figure 2 suggests that the arrival at Reunion island of air masses originating from midlatitudes induces a positive anomaly on ozone, if the transport is occurring below $625 \mathrm{~K}$, and a negative anomaly if the 


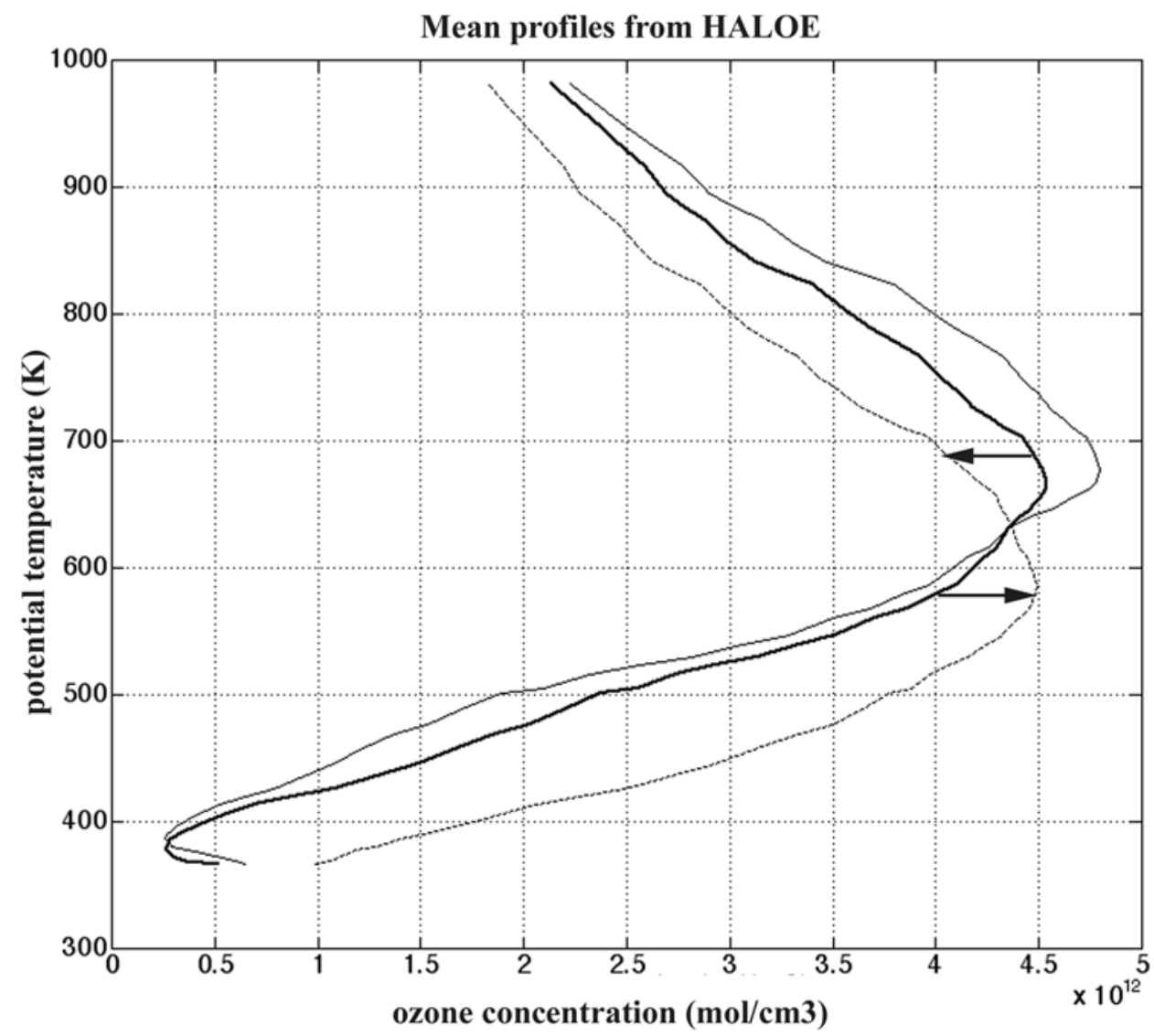

Figure 2. Climatological ozone concentration profiles versus potential temperature for different zonal areas. Thick solid line corresponds to Reunion station latitude $\left(21^{\circ} \mathrm{S}\right)$, thin solid line corresponds to equatorial latitudes $\left(10^{\circ} \mathrm{S}\right)$, and dashed line corresponds to midlatitudes $\left(40^{\circ} \mathrm{S}\right)$. These profiles are derived from HALOE measurements.

transport is taking place above this level. This inference is in close agreement with the ozone profile anomalies observed on 12 July. An increase of concentration is observed below $625 \mathrm{~K}$ and a decrease above $625 \mathrm{~K}$.

\section{Lamina Origin}

\subsection{Epv Temporal Evolution}

[13] Isentropic Ertel's potential vorticity (Epv) was derived from ECMWF reanalyses, with a horizontal $1^{\circ} \times 1^{\circ}$ grid and 10 isentropic levels in the lower stratosphere. From these fields, an Epv climatology based on 1992-2000 data is established at the location of Reunion site. Figure 3 presents the evolution of Epv during austral winter 2000, against the climatological Epv, on 3 isentropic levels $(550,600$ and $700 \mathrm{~K})$. The Epv time series above Reunion displays an anomaly, significant at $2 \sigma$ level, on 12 July 2000. This anomaly is positive and corresponds to a very large Epv air. Since Epv is expected to be a good dynamical tracer [Hoskins et al., 1985; Holton et al., 1995], this signature evidences the arrival of an air mass coming from a distant origin at Reunion.

[14] Southern hemisphere Epv is conventionally negative. Yet, since this study considers data from the southern hemisphere only, absolute Epv values (positive Epv) are used for convenience, i.e., low Epv values correspond to low latitudes air and high Epv values to midlatitudes.

\subsection{Visualization of the Lamina by the DYBAL and MIMOSA Models}

[15] The subtropical barrier deformation is inferred from a software code (DYBAL) using area coordinates and Nakamura's formalism [Nakamura, 1996]. Provided that the motions of a tracer $\mathrm{q}$ are adiabatic and nondivergent, $\mathrm{q}$ mixing is diagnosed using $\mathrm{A}(\mathrm{K})$, defined as the normalized area of Earth for which $q$ is greater or equal to a $K$ value of q. $\mathrm{A}(\mathrm{K})$ is normalized by its maximum possible value, i.e., $2 \pi R^{2}$ for the hemisphere. By definition, $A(K)$ is a monotonic function of $\mathrm{K}$ and it is convenient to use a latitude coordinate $\phi$ named "equivalent latitude" and defined by

$$
\phi=\arcsin (\mathrm{A}(\mathrm{K}))
$$

Provided that the diffusion coefficient $\mathrm{k}$, representative of small unresolved scales, is constant, the tracer concentration q satisfies the diffusion equation (2a):

$$
\frac{d q}{d t}=k \frac{d}{d A}\left[L_{e q}^{2} \frac{d q}{d A}\right]
$$




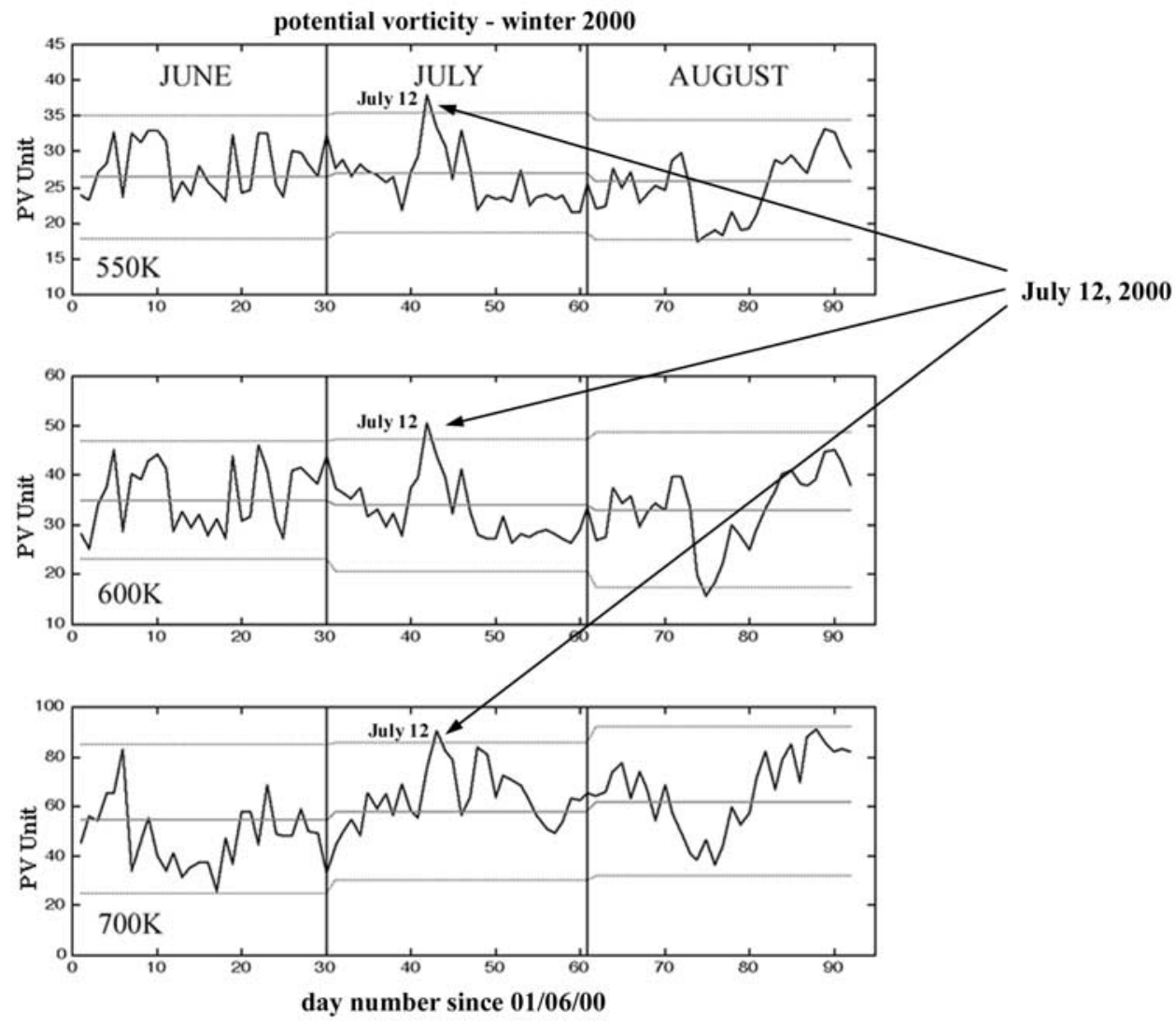

Figure 3. Epv temporal evolution at 550, 600, and $700 \mathrm{~K}$ above Reunion island during austral winter 2000 compared with monthly 1992-2000 averaged values (solid horizontal lines). Dashed horizontal lines correspond to $2 \sigma$ standard deviation of the climatological values.

where $\mathrm{L}_{\text {eq }}$ is the equivalent length of the tracer contour, defined by Nakamura [1996] as

$$
\begin{gathered}
\mathrm{L}_{\mathrm{eq}}^{2}(\mathrm{~A}, \mathrm{t})=\frac{\left(\overline{|\nabla q|^{2}}\right)}{(\partial q / \partial A)^{2}} \\
\text { or } \mathrm{L}_{\mathrm{eq}}^{2}(\phi, \mathrm{t})=\left(2 \pi R^{2} \cos \phi\right)^{2} \frac{\left(\overline{|\nabla q|^{2}}\right)}{(\partial q / \partial \phi)^{2}}
\end{gathered}
$$

$\overline{|\nabla q|^{2}}$ in equation (2c) is defined by :

$$
\overline{|\nabla q|^{2}}=\frac{\oint|\nabla q| d l}{\oint \frac{d l}{|\nabla q|}}
$$

$\mathrm{L}_{\text {eq }}^{2}$ determines the mixing efficiency. Large-scale movements through $\mathrm{L}_{\mathrm{eq}}$ are amplifying small-scale diffusion and an effective diffusivity $\mathrm{k}_{\text {eff }}$ can be defined by (3) [Haynes and Shuckburgh, 2000; Nakamura, 2001].

$$
k_{e f f}(\phi, t)=\frac{k L_{e q}^{2}(\phi, t)}{(2 \pi r \cos \phi)^{2}}
$$

As indicated by Nakamura [1996], $\mathrm{L}_{\mathrm{eq}}$ (or $\mathrm{k}_{\mathrm{eff}}$ ) is larger when the contour tracer is more complex, i.e., where largescale mixing is stronger.

[16] The Epv gradient in area coordinate $\frac{\partial q}{\partial A}$ (or $\frac{\partial q}{\partial \phi}$ in equivalent latitude coordinate) and $\mathrm{L}_{\mathrm{eq}}^{2}$ are diagnostic tools inferred by Nakamura [1996] to identify weak mixing and transport barrier. They are expected to display, respectively, a local maximum and a local minimum at a barrier position. Since Epv is conservative for adiabatic and non dissipative movements, we presently use Epv as q tracer on isentropic surfaces.

[17] The DYBAL code uses simultaneously both diagnostic tools to position the dynamical barrier on 5 isentropics levels $(400,450,500,600$ and $700 \mathrm{~K})$ with $1^{\circ} \times 1^{\circ}$ horizontal grid resolution, i.e., DYBAL selects an area of equivalent latitudes where $\mathrm{L}_{\text {eq }}^{2}(\phi, \mathrm{t})$ is minimum and $\frac{\partial(E p v)}{\partial \phi}$ maximum. It is then possible to determine Epv values corresponding to low mixing areas and to infer barrier location by reversing to Cartesian coordinates using equation (1). These tools are usually used separately to detect mean barrier position [Nakamura, 1996, 2001]. Yet, it is also possible to use them on successive instantaneous fields in order to determine how the barrier warps and collapses. DYBAL method is presently used to detect dynamical barrier distortions from instantaneous fields of quasi-conservative tracers.

[18] DYBAL outputs using Epv on the $550 \mathrm{~K}$ surface for dates around 12 July 2000 are presented on Figure 4. 

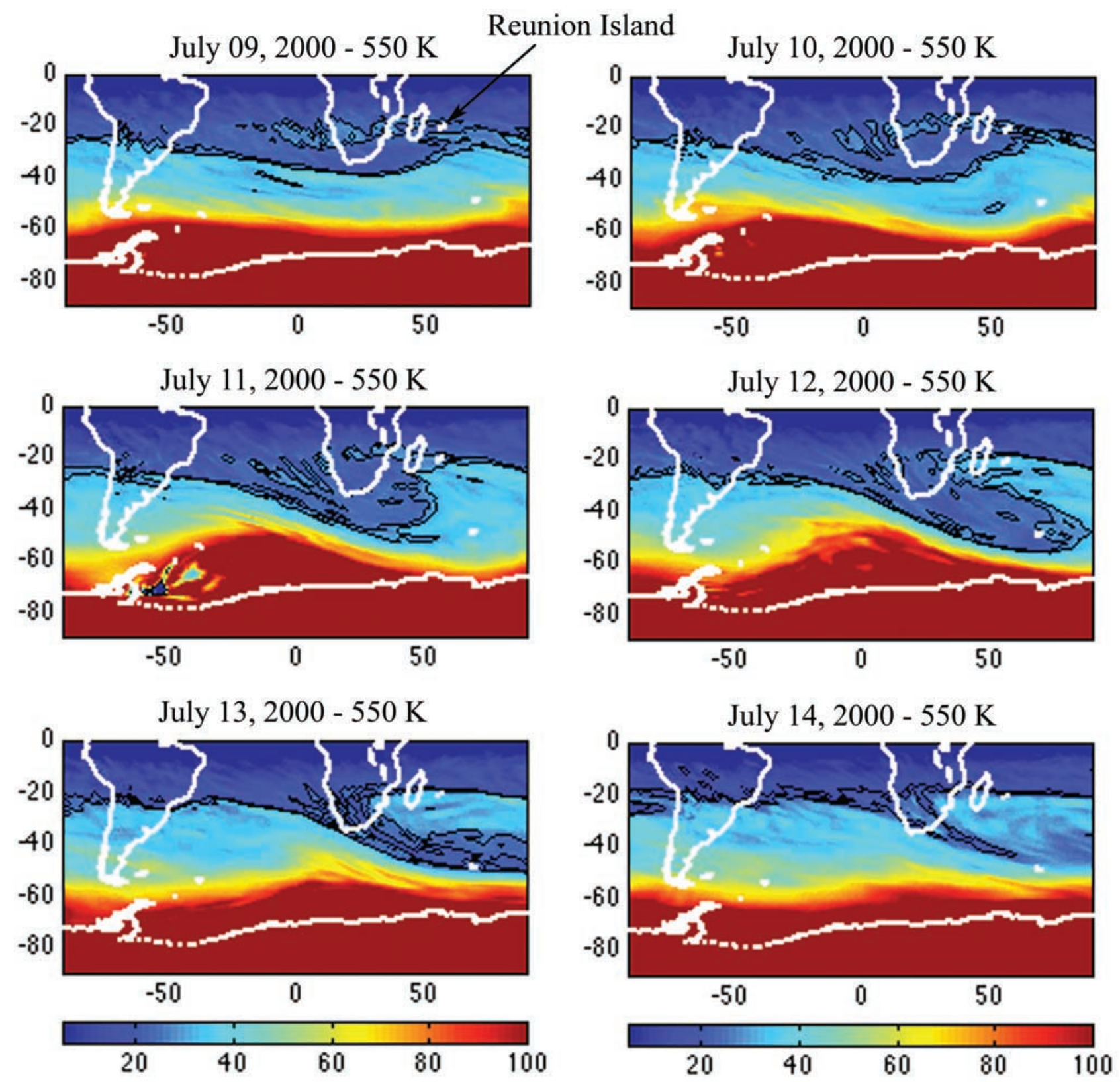

Figure 4. Subtropical stratospheric barrier evolution at $550 \mathrm{~K}$ around 12 July 2000 calculated with DYBAL code based on Nakamura's diagnostic tools. Barrier position (black contour) is superimposed on Epv maps using color scale with Epv units.

Reunion island, located to the east of Madagascar, is under the influence of equatorial air before 10 July. On 10 July the subtropical dynamical barrier is approaching Reunion island and from 11 July the stratosphere above this site is under the influence of midlatitudes air. Although the midlatitude influence is beginning on 11 July, the main effect on Epv is observed on 12 July (Figure 2). As visible on Figure 4 the subtropical barrier is initially positioned around $25^{\circ} \mathrm{S}$. From 10 July, it begins to bend above South Africa creating a large tongue of low Epv that stretches during the following days toward the southern Indian Ocean. The downward movement of low PV to the south is associated with a coincident upward movement of midlatitudes air to the north. It is this high Epv air originating from midlatitudes that influences Reunion island since 12 July. Model outputs for the following days show that Reunion stays under the influence of this high Epv core until 15 July (figures not shown). After this date, the low Epv tongue further stretches to the East-South-East and is completely mixed in the surf zone around 20 July.

[19] This event was also investigated using the high resolution Epv contour advection model MIMOSA [Hauchecorne et al., 2002] on isentropic surfaces. The model runs on an orthogonal grid covering the whole southern hemisphere with a resolution of 3 grid points/degree. Epv at each grid point is advected using ECMWF winds and the advected fields are reinterpolated on the original grid every 6 hours. In addition, MIMOSA runs are relaxed toward 

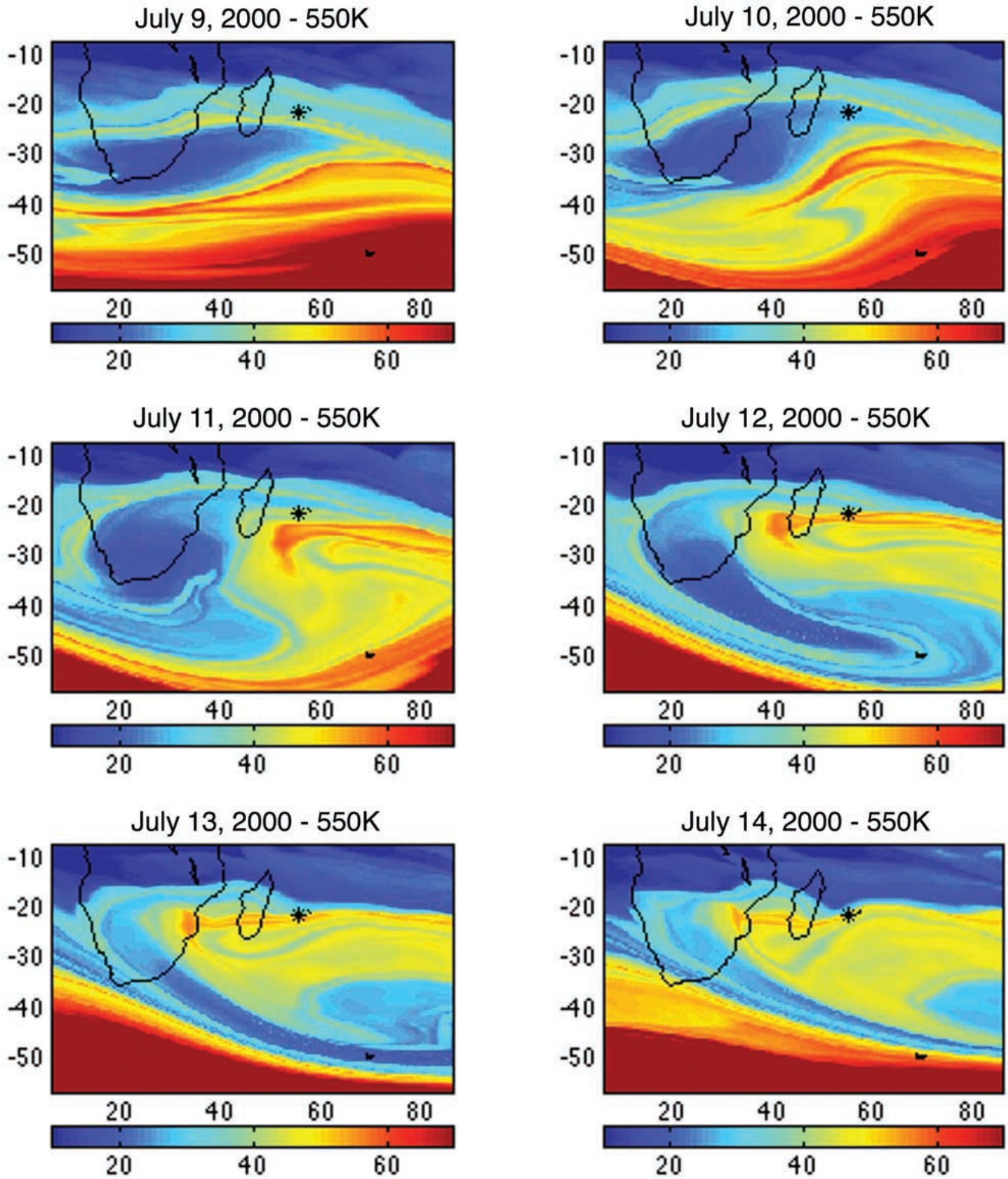

Figure 5. Epv maps advected with the high resolution model MIMOSA. Outputs are calculated on 600 K level every 24 hours between 9 and 14 July 2000. The Epv values are given by a color scale in Epv units.

ECMWF Epv fields with a 10 days time constant in order to take into account diabatic transport for periods longer than 2 weeks. Output maps from MIMOSA zoomed on the southern part of the Indian Ocean are shown on Figure 5. Best resolution of modeled Epv fields $\left(0.3^{\circ} \times 0.3^{\circ}\right)$ allows us to more accurately document the midlatitude air filament passing above Reunion. Consistent with DYBAL, MIMOSA advection model reveals the formation of a low Epv filament around 9 July in the southern part of the African continent and a high Epv tongue coming from midlatitudes 


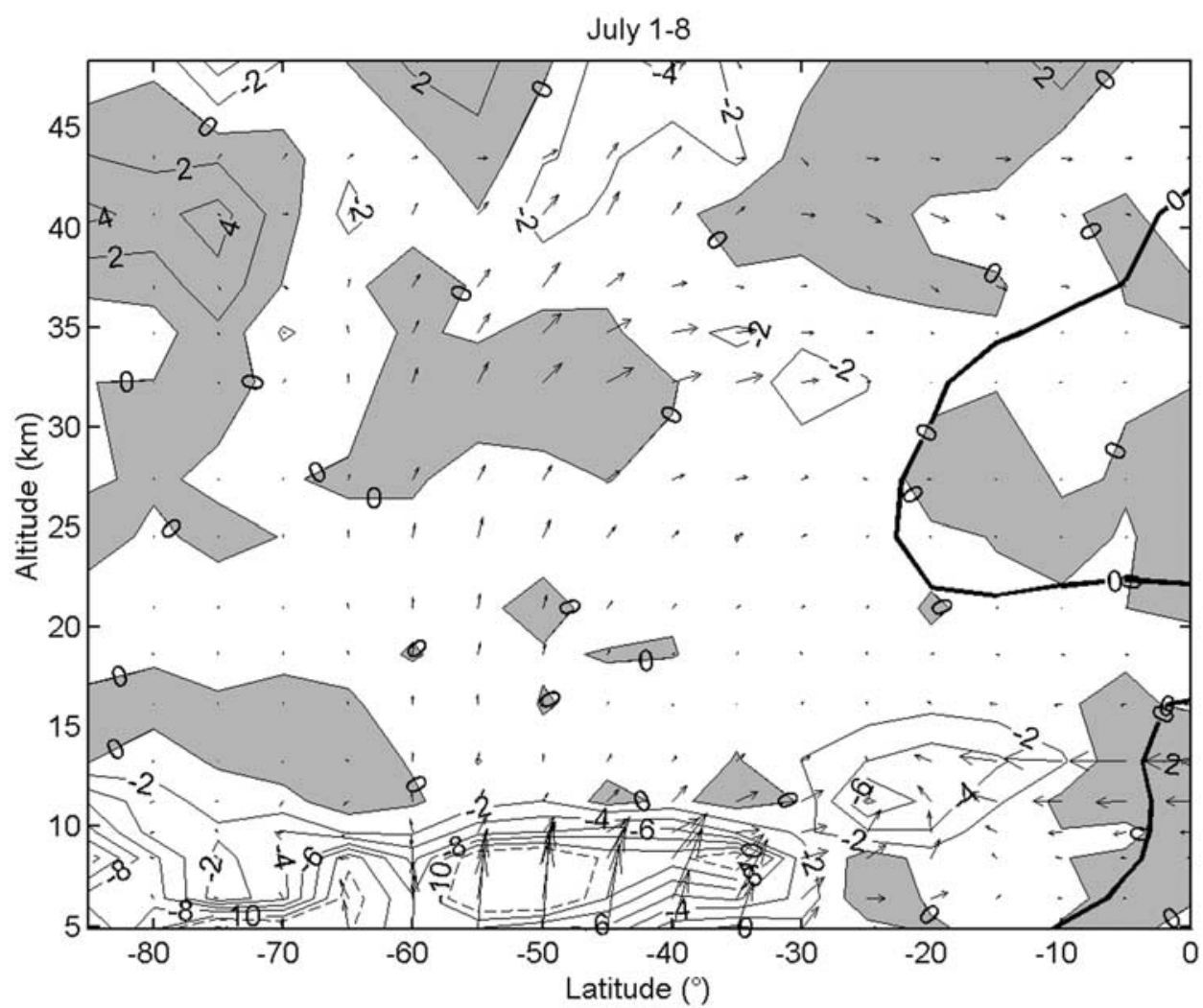

Figure 6. E-P flux cross sections in the meridional plane averaged over 1-8 July. Contours represent values of the wave driving term $\mathrm{D}$ (see text for definition), in $\mathrm{m} \mathrm{s}^{-1}$ per day; positive wave driving is shaded. The contour interval is $2 \mathrm{~m} \mathrm{~s}^{-1}$ per day, and dashed contours correspond to values more than 10 $\mathrm{m} \mathrm{s}^{-1}$ per day or less than $-10 \mathrm{~m} \mathrm{~s}^{-1}$ per day. Zero wind line has been overlaid (thick solid contour).

and reaching Reunion on 12 July. Additional DYBAL and MIMOSA runs indicate a similar evolution at $550 \mathrm{~K}$ and $700 \mathrm{~K}$. Below $500 \mathrm{~K}$ and above $750 \mathrm{~K}$, no filamentation is observed (data not shown). These model results further corroborate the large vertical extension and the level of occurrence of the lamina detected by the ozonesonde data (Figure 1).

[20] Besides, the present consistency between observational data and Epv signatures calculated from ECMWF fields corroborate other studies [Baray et al., 2000] showing that ECMWF analyses are quite reliable and accurate in the southern tropics.

\section{Linkage to Planetary Wave Activity}

[21] The rapid and irreversible deformation of Epv contours on the $600 \mathrm{~K}$ surface observed on Figure 5 suggests a planetary wave breaking linkage [McIntyre and Palmer, 1984]. Further diagnostics of the planetary wave activity and possible wave-breaking regimes are provided by the Eliassen-Palm (E-P) flux vector $\vec{F}$, and its divergence $\nabla \vec{F}$. We use the quasi-geostrophic version of $\vec{F}$ in spherical geometry expressed as:

$$
\vec{F}=\left\{F_{(\phi)}, F_{(z)}\right\}=\left\{-\rho_{0} R \cos \phi\left(\overline{v^{\prime} u^{\prime}}\right), f \rho_{0} R \cos \phi\left[\overline{\frac{v^{\prime} \theta^{\prime}}{\overline{\theta_{z}}}}\right]\right\}
$$

where overbar and prime denote respectively zonal mean and deviation from this mean; other notations are standard [Andrews et al., 1987]. E-P flux pattern for planetary waves is representative of the transfer of wave activity density vertically and in the meridional direction [Kanzawa, 1984]. Quasi-stationary, midlatitude winter planetary waves are known to propagate upward from the troposphere into the stratosphere, and meridionally toward the equatorial regions. Figures 6 and 7 show E-P cross sections computed using ECMWF fields, with arrows representing the E-P flux vectors, and contours of the wave driving $D=\frac{1}{\rho_{0} R \cos \phi} \vec{\nabla} \cdot \vec{F}$, averaged over the periods 1-8 July and 9-14 July, respectively. Planetary wave breaking is identified by the convergence of the E-P flux (i.e., negative D in Figures 6 and $7)$. The comparison between Figures 6 and 7 shows an increase in stratospheric wave activity after 8 July. Indeed, a strong upward wave propagation in the lower stratosphere is observed over $45^{\circ}-65^{\circ} \mathrm{S}$ during the 9-14 July period (Figure 7). The E-P flux vectors bend equatorward with height and generate a large region of convergence (negative D) between 25 and $40 \mathrm{~km}$ northward of $50^{\circ} \mathrm{S}$. D reaches a minimum of approximately $-8 \mathrm{~m} \mathrm{~s}^{-1}$ per day near $35^{\circ} \mathrm{S}$ and $35 \mathrm{~km}$ height. Much of the wave activity that reaches the tropical stratosphere at this time originates from the upper troposphere of middle and high latitudes, as suggested by the positive values of $\mathrm{D}$ in Figure 7. The E-P activity is particularly strong on 12 July (data not shown) and is associated with a greater wave penetration and an 


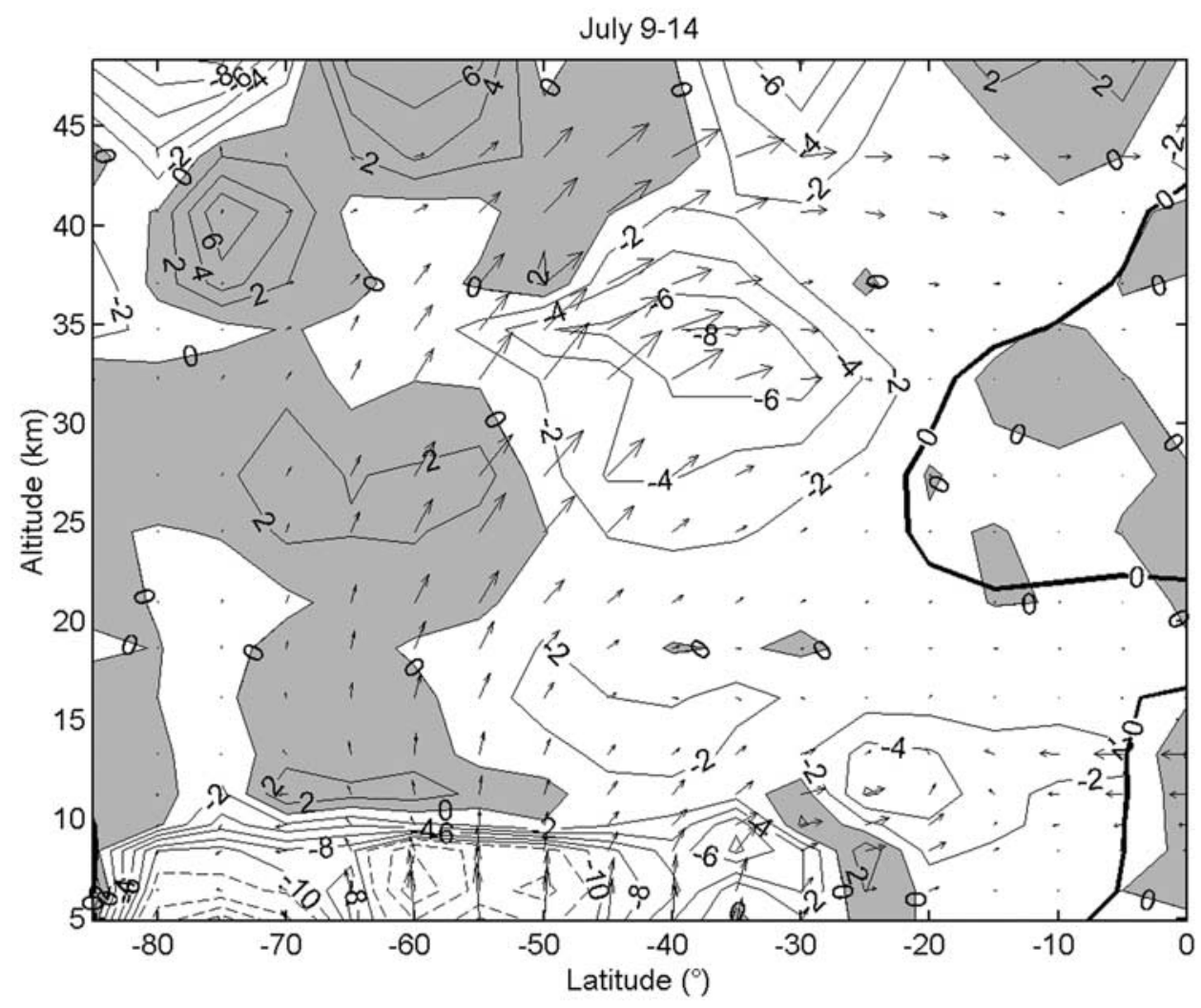

Figure 7. Same as Figure 6 over 9-14 July.

enhanced wave driving in the subtropical middle stratosphere, where D reaches a minimum lower than $-10 \mathrm{~m} \mathrm{~s}^{-1}$ per day near $35 \mathrm{~km}$ and $30^{\circ} \mathrm{S}$. This analysis suggests that the strong filament observed on 12 July is produced by the erosion of the subtropical barrier caused by a vigorous wave breaking in the surf zone during that time. Wave breaking in this stratospheric zone is likely to result from the presence of critical lines for planetary-scale Rossby wave propagation [McIntyre and Palmer, 1984]. During winter, the onset of westerlies enables the vertical propagation of planetaryscale waves into the stratosphere, where they are expected to break as they encounter a critical line. Since the zonal wind is westerly, it is likely that this event involves quasistationary and/or slow eastward components.

\section{Conclusion}

[22] Although large amplification by filaments of smallscale diffusivity has take advantage of recent insights [Nakamura, 1996; Haynes and Shuckburg, 2000], most studies on this topic focus on 2-D investigations on isentropic levels. Correlation through synchronized mechanisms between different levels and the vertical extension of laminae are generally not addressed, especially in the tropics. Yet, turbulent transport through dynamical barriers and between isentropic levels, and mean flow drag induced by wave breaking, are also dependent on vertical extension of large-scale movements and on synergy between levels. Hence some additional attention should be dedicated to fine-scale vertical investigation of laminae using high resolution vertical profiles from in situ stations or satellite platforms. In the present investigation, vertical soundings of stratospheric ozone, recorded at Reunion station, documents the large vertical extension $(500$ to $700 \mathrm{~K})$ and the high level of occurrence of a filament reaching this station around 12 July 2000 . The dynamical barrier detection code (DYBAL) and MIMOSA advection model both diagnosed a midlatitude origin for this filament. Furthermore, it is shown that this high Epv tongue results from the formation of a low Epv filament coming from the tropics that first stretches to the south-east and then mixes along isentropic surfaces in the midlatitude surf zone.

[23] The redistribution by such laminae/filaments of already ozone-depleted air from midlatitudes into the tropics, is likely to contribute to the ozone redistribution in the stratosphere at higher levels than usually stated [Grant et $a l ., 1998]$ and indirectly to the weak but significant decrease of total ozone observed in tropical regions [World Meteorological Organization, 1998]. Other papers [Jost et al., 1998] have reported laminae at high altitude inside the TSR linked to transport events from midlatitudes. Moreover, an ongoing study on systematic detection of laminae in ozone profile data set from Reunion, suggests that the present case study is not isolated. From this study which investigates the vertical extension of these events occurring throughout the year, it should be possible to estimate the entrainment of midlatitude air into the tropics in a statistical way.

[24] In addition, it should be valuable to check whether Reunion is situated on a preferential route for the winter transport similar to privileged routes evidenced by Horinouchi et al. [2000] or Orsolini and Grant [2000] in the northern hemisphere lower stratosphere.

[25] Acknowledgments. We would like to thank the LPA radiosounding team and F. Posny, the P.I. of soundings at Reunion Island. We 
wish to thank the technical and scientific lidar team from the Service d'Aéronomie of CNRS. Particularly, we want to thank C. Flesia of Geneva University for implementing the stratospheric ozone lidar at Reunion island and C. Hirt of Geneva University and J. Porteneuve of the Service d'Aéronomie for their work on Reunion DIAL lidar system. Ozone soundings at Reunion Island are partially supported by the SHADOZ program from the NASA/Goddard Space Flight Center. HALOE data are issued from NASA Langley Research Center. The ECMWF is also acknowledged for providing model analyses.

\section{References}

Andrews, D. G., J. R. Holton, and C. B. Leovy, Middle Atmosphere Dynamics, Academic, San Diego, Calif., 1987.

Baldwin, M. P., et al., The quasi-biennial oscillation, Rev. Geophys, 39, 179-229, 2001

Baldy, S., G. Ancellet, M. Bessafi, A. Badr, and D. Lan-Sun-Luk, Field observations of the vertical distribution of tropospheric ozone at the Island of La Reunion, J. Geophys. Res., 101, 23,835-23,850, 1996.

Baray, J. L., V. Daniel, G. Ancellet, and B. Legras, Planetary-scale tropopause fold in the southern subtropics, Geophys. Res. Lett., 27, 353-356, 2000

Chen, P., J. R. Holton, A. O’Neill, and R. Swinbank, Isentropic mass exchanges between tropics and extratropics in the stratosphere, J. Atmos. Sci., 51, 3006-3018, 1994

Choi, W., W. B. Grant, J. H. Park, K. M. Lee, H. Lee, and J. M. Russel III, Role of the quasi biennial oscillation in the transport of aerosols from the tropical stratosphere to mid-latitudes, J. Geophys. Res., 103, 6033-6042, 1998

Grant, W. B., E. V. Browell, C. S. Long, L. L. Stowe, R. G. Grainger, and A. Lambert, Use of volcanic aerosols to study the tropical stratospheric reservoir, J. Geophys. Res., 101, 3973-3988, 1996.

Grant, W. B., R. Bradley Pierce, S. J. Oltmans, and V. Edward, Seasonal evolution of total and gravity wave induced laminae in ozonesonde data in the tropics and subtropics, Geophys. Res. Lett., 25, 1863-1866, 1998

Hall, T. M., and D. W. Waugh, Tracer transport in the tropical stratosphere due to vertical diffusion and horizontal mixing, Geophys. Res. Letters, 24, 1383-1386, 1997.

Hauchecorne, A., S. Godin, M. Marchand, B. Heese, and C. Souprayen, Quantification of the transport of chemical constituents from the polar vortex to midlatitudes in the lower stratosphere using the high-resolution advection model MIMOSA and effective diffusivity, J. Geophys. Res., 107(D20), 8289, doi:10.1029/2001JD000491, 2002.

Haynes, P., and E. Shuckburgh, Effective diffusivity as a diagnostic of atmospheric transport, 1, Stratosphere, J. Geophys. Res., 105, 22,777$22,794,2000$

Heese, B., S. Godin, and A. Hauchecorne, Forecast and simulation of stratospheric ozone filaments: A validation of a high-resolution potential vorticity advection model by airborne ozone lidar measurements in winter 1998/1999, J. Geophys. Res., 106, 20,011-20,024, 2001.

Hitchman, M. H., M. McKay, and C. R. Trepte, A climatology of stratospheric aerosol, J. Geophys. Res., 99, 20,689-20,700, 1994.

Holton, J. R., P. H. Haynes, M. E. McIntyre, A. R. Douglass, R. B. Rood and L. Pfister, Stratosphere-troposphere exchange, Rev. Geophys., 33, 403-439, 1995.

Horinouchi, T., F. Sassi, and A. Boville, Synoptic-scale waves and the geographic distribution of lateral routes between the tropics and the extratropics in the lower stratosphere, J. Geophys. Res., 105, 26,57926,592, 2000

Hoskins, B. J., M. E. McIntyre, and A. W. Robertson, On the use and significance of isentropic potential vorticity maps, Q. J. R. Meteorol. Soc., 111, 877-946, 1985.

Jost, H., M. Loewenstein, L. Pfister, J. J. Margitan, A. Y. Chang, R. J. Salawitch, and H. A. Michelsen, Laminae in the tropical middle stratosphere: Origin and age estimation, Geophys. Res. Lett., 25, 4337-4340, 1998. (Correction, Geophys. Res. Lett., 26, 479, 1999. )

Kanzawa, H., Four observed sudden stratospheric warmings diagnosed by the Eliassen-Palm flux and refractive index, in Dynamics of the Middle Atmosphere, edited by J. R. Holton and T. Matsuno, pp. 307-331, Terra Sci., Tokyo, 1984.

Komhyr, W. D., R. A. Barnes, G. B. Brothers, J. A. Lasthrop, and D. P. Opperman, Electrochemical concentration cell ozonesonde performance evaluation during STOIC 1989, J. Geophys. Res., 9231-9244, 1995.
Mariotti, A., M. Moustaoui, B. Legras, and H. Teitelbaum, Comparison between vertical ozone soundings and reconstructed potential vorticity maps by contour advection with surgery, J. Geophys. Res., 102, 6131$6142,1997$.

McCormick, M. P., and R. E. Veiga, SAGE II measurements of early Pinatubo aerosols, Geophys. Res. Lett., 19, 155-158, 1992.

McIntyre, M. E., and T. N. Palmer, The "surf zone" in the stratosphere, J. Atmos. Terr. Phys., 46, 825-849, 1984.

Mote, P. W., T. J. Dunkerton, M. E. McIntyre, E. A. Ray, P. H. Haynes, and J. M. Russel III, Vertical velocity, vertical diffusion, and dilution by midlatitude air in the tropical lower stratosphere, J. Geophys. Res., 103, 8651-8666, 1998 .

Nakamura, N., Two-dimensional mixing, edge formation, and permeability diagnosed in an area coordinate, J. Atmos. Sci., 53, 1524-1537, 1996.

Nakamura, N., A new look at eddy diffusivity as a mixing diagnostic, J. Atmos. Sci., 58, 3685-3701, 2001.

Orsolini, Y. J., and W. B. Grant, Seasonal formation of nitrous oxide laminae in the mid and low latitude stratosphere, Geophys. Res. Lett, 27, $1119-1122,2000$

Orsolini, Y. J., G. Hansen, U. P. Hoppe, G. L. Manney, and K. H. Fricke, Dynamical modelling of wintertime lidar observations in the arctic: Ozone laminae and ozone depletion, O. J. R. Meteorol. Soc., 123, $785-800,1997$

Orsolini, Y. J., G. L. Manney, A. Engel, J. Ovarlez, C. Claud, and L. Coy, Layering in stratospheric profiles of long-lived trace species: Balloonborne observations and modeling, J. Geophys. Res., 103, 5815-5825, 1998.

Posny, F., T. Portafaix, J. L. Baray, S. Baldy, and J. Leveau, Measurement of vertical ozone distributions at La Réunion Island (southern tropics), paper presented at Quadriennal Ozone Symposium, Hokkaido University, Sapporo, Japan, 2000

Reid, S. J., and G. Vaughan, Lamination in ozone profiles in the lower stratosphere, O. J. R. Meteorol. Soc., 117, 825-844, 1991.

Roger, H. L., W. A. Norton, A. Lambert, and R. G. Grainger, Transport of Mt Pinatubo aerosol by tropospheric synoptic-scale and stratospheric planetary-scale waves, Q. J. R. Meteorol. Soc., 124, 193-209, 1998.

Roger, H. L., W. A. Norton, A. Lambert, and R. G. Grainger, Isentropic, diabatic, and sedimentary transport of Mount Pinatubo aerosol, J. Geophys. Res., 104, 4051-4063, 1999.

Rosenlof, K. H., A. F. Tuck, K. K. Kelly, J. M. Russell, and M. P. McCormick, Hemispheric asymmetries in water vapor and inferences about transport in the lower stratosphere, J. Geophys. Res., 102, 13,213$13,234,1997$

Russell, J. M., III, L. L. Gordley, J. H. Park, S. R. Drayson, A. F. Tuck, J. E. Frederick, J. E. Harries, and P. J. Crutzen, The halogen occultation experiment, J. Geophys. Res., 98, 10,777-10,797, 1993.

Shuckburgh, E., W. Norton, A. Iwi, and P. Haynes, Influence of the quasibiennial oscillation on isentropic transport and mixing in the tropics and subtropics, J. Geophys. Res., 106, 14,327-14,337, 2001

Thompson, A. M., et al., Southern Hemisphere Additional Ozonesondes (SHADOZ) 1998-2000 tropical ozone climatology, 1, Comparison with Total Ozone Mapping Spectrometer (TOMS) and ground-based measurements, J. Geophys. Res., 108(D2), 8238, doi:10.1029/2001JD000967, 2003

Trepte, C. R., and M. H. Hitchman, Tropical stratospheric circulation deduced from satellite aerosol data, Nature, 355, 626-628, 1992.

Waugh, D. W., Seasonal variation of isentropic transport out of the tropical stratosphere, J. Geophys. Res., 101, 4007-4023, 1996.

Waugh, D. W., et al., Transport of material out of the stratospheric arctic vortex by Rossby wave breaking, J. Geophys. Res., 99, 1071-1088, 1994.

World Meteorological Organization, Assessment of trends in the vertical distribution of ozone, Global Ozone Res. Monit. Proj. Rep. 43, Geneva, Switzerland, 1998.

S. Baldy, H. Bencherif, B. Morel, and T. Portafaix, Laboratoire de Physique de l'Atmosphère, Reunion University, Avenue Rene Cassin, BP 7151, St. Denis, 97715 Reunion, France.

S. Godin-Beekmann, Alfred Wegener Institut, Telegrafenberg A 43, 14473 Potsdam, Germany.

A. Hauchecorne, Service d'Aéronomie, Réduit de Verrières, BP 3, Route des Gatines, 91371 Verrières le Buisson Cédex, France. 